\title{
Dilemas e vicissitudes de famílias em situação de vulnerabilidade social no contexto da desinstitucionalização psiquiátrica
}

| ${ }^{1}$ Tarcisa Bezerra Gomes, ${ }^{2}$ João Bosco Feitosa dos Santos |

Resumo: Este artigo objetiva desvelar os dilemas e vicissitudes das famílias em situação de vulnerabilidade social no contexto hodierno da desinstitucionalização psiquiátrica. De natureza quanti-qualitativa, com suporte bibliográfico, documental, entrevista semiestruturada e observação flutuante, a pesquisa foi feita na Defensoria Pública da União no Ceará e teve como sujeitos famílias com demanda psíquica atendidas pelo serviço social da instituição, as quais buscam assistência jurídica para a obtenção de direitos sociais destinados à pessoa com deficiência mental, que lhes são negados no âmbito administrativo. A pesquisa revelou que os familiares enfrentam dilemas e vicissitudes tanto na esfera microfamiliar, através dos conflitos que envolvem questôes financeiras, físicas e emocionais marcadas pelas pressões e sobrecargas adjuntas à situação, quanto na esfera macrossocial, devido ao crescente processo de centralização familiar, em face da desproteção do Estado, e às mazelas estruturais de uma conjuntura política pautada por interesses globais e econômicos que reverberam no provimento da política de proteção social. Conclui-se, pois, que tais questôes precisam ser amplamente discutidas no sentido de atentar para as demandas familiares, visto que não responder aos seus anseios e necessidades pode incorrer em riscos para os avanços da desinstitucionalização psiquiátrica.
1 Defensoria Pública da União e Universidade Estadual do Ceará. Fortaleza-CE, Brasil (tarcisa. gomes@gmail.com).

${ }^{2}$ Universidade Estadual do Ceará. Fortaleza-CE, Brasil (feitosabosco@gmail.com). 


\section{Introdução}

O Movimento da Reforma Psiquiátrica, principiado em 1970, conquistou espaço social e fomentou a desinstitucionalização psiquiátrica, modelo vigente na atual política de saúde mental brasileira que prioriza o cuidado, a atenção em base territorializada e a reinserção social do acometido por sofrimento mental. A este é dado o direito de ser visto e defendido como cidadão, o que difere da estratégia de institucionalização, pautada no modelo hospitalocêntrico e asilar, que se caracterizou pela violência e desrespeito à dignidade humana, cujas configurações podem ser mais bem compreendidas em Castel (1978), Foucault (2012) e Goffman (2013).

Contudo, ao passo em que os avanços na saúde mental se fazem notar, especialmente no âmbito formal, a contemporaneidade revela desafios ao modelo em curso engendrados nas mudanças político-econômicas do projeto neoliberal de corte público e de reestruturação no mundo do trabalho (VASCONCELOS, 2010). Desafios que também reverberam na dinâmica das famílias socialmente vulneráveis, cujos parentes em sofrimento são usuários dos Centros de Atenção Psicossocial (CAPS).

A família, com base nas diretrizes organizacionais da desinstitucionalização psiquiátrica, assume hoje papel relevante na política de saúde mental, na medida em que é parte integrante do processo e postula-se como extensão do tratamento ao parente adoecido mentalmente. Portanto, mais do que nunca, fazse necessário olhar para a família, conhecer suas demandas e anseios (BRASIL, 2011; DELGADO, 2014; DIMENSTEIN et al., 2010).

Denominada de "familismo" ou "familização" (TEIXEIRA, 2013), a redescoberta das famílias nas políticas públicas é fenômeno originário dos anos 1970 que eclodiu com a crise do Estado de Bem-Estar Social. Hodiernamente, vem ganhando destaque com o ascendente recuo do poder público no provimento social e, por conseguinte, no incentivo à corresponsabilidade envolvendo família, sociedade e mercado (CARVALHO, 2001; MIOTO, 2009; PEREIRA, 2009, TEIXEIRA, 2013). Desta feita, na turbulência social atual, um movimento paradoxal se instaura: se, de um lado, cabe à família o papel de centralidade nas políticas sociais, inclusive na saúde mental; por outro, o mesmo segmento sofre os efeitos perversos com a desresponsabilização crescente do Estado nas políticas sociais, agudizando especialmente os contextos familiares mais vulneráveis. 
Nesse sentido, Castel (1997) assevera que tal vulnerabilidade representa a zona intermediária entre a integração e a desfiliação, configurando-se como espaço de instabilidade no qual indivíduos têm vínculos precários e frágeis tanto no trabalho quanto na sua inserção relacional, ou, como diria Pizarro (2001), é um conceito que não se restringe somente ao aspecto da pobreza, mas apresenta outros determinantes e, por isso, permite melhor compreensão dos impactos das transformações do novo padrão de desenvolvimento social. Assim, em sendo parte significante da desinstitucionalização psiquiátrica, torna-se imperioso analisar a família no contexto hodierno de sua implementação, marcada então por desafios, no sentido de possibilitar abertura para posicionamentos e manifestações das demandas e necessidades do segmento como forma de contribuir para os avanços do processo em curso da saúde mental e diluir possíveis riscos à sua consolidação.

\section{Metodologia}

Este texto teve como principal fonte teórica e empírica a pesquisa de mestrado intitulada A família em situação de vulnerabilidade social no contexto hodierno da desinstitucionalização psiquiátrica, realizada na Defensoria Pública da União no Ceará (DPU/CE), tendo como sujeitos as famílias em situação de vulnerabilidade social com demanda psíquica atendidas pelo Serviço Social da instituição, que buscam assistência jurídica para a obtenção de direitos sociais destinados à pessoa com deficiência mental, os quais lhes são negados no âmbito administrativo. Com enfoque pluralista, a investigação orientou-se na abordagem histórico-crítica e cultural, com vistas a dar conta da complexidade e amplitude das categorias adotadas: família, vulnerabilidade social e desinstitucionalização psiquiátrica. Outrossim, teve natureza quanti-qualitativa, adotando elementos bibliográficos e documentais e utilizando a entrevista semiestruturada e a observação flutuante.

Aprioristicamente, realizou-se levantamento dos casos com demanda psiquiátrica, entre janeiro e dezembro de 2013, atendidos no Serviço Social da DPU/CE, sendo detectadas 56 famílias. A partir desse universo, realizou-se estudo descritivo dos dados coletados, a fim de se traçar o perfil dos sujeitos da investigação. $O$ passo seguinte foi definir as famílias para a entrevista, sendo escolhidas 16, tendo como alvo os representantes legais que detêm a curatela ou tutela do assistido. Os critérios de seleção foram: atendimento em serviço assistencial de saúde mental no CAPS, renda abaixo de dois salários mínimos, 
requerimento da concessão do amparo assistencial e famílias com parente em adoecimento mental severo (esquizofrenia, bipolaridade e retardo mental grave), especialmente com histórico de internação psiquiátrica.

As entrevistas ocorreram, em sua maioria, na DPU. Algumas se deram na casa das famílias, pelas dificuldades de deslocamento dos entrevistados até a instituição. Ressalva-se que os participantes assinaram os Termos de Consentimento Livre e Esclarecido e que o estudo foi submetido ao Comitê de Ética e Pesquisa da Universidade Estadual do Ceará (CEP/UECE), aprovado com o Parecer n. ${ }^{\circ}$ 985.626/2015. Todos os sujeitos da pesquisa foram informados quanto aos objetivos do projeto e procedimentos metodológicos, bem como sobre os possíveis riscos e benefícios e o compromisso dos pesquisadores em relação à confidencialidade das informaçóes e da identidade dos participantes. Todos os depoentes forneceram consentimento, conforme as normas e princípios da Declaração de Helsinque e da Resolução n. ${ }^{\circ}$ 196/96, do Conselho Nacional de Saúde. Os autores asseveram não existir conflito de interesse.

As entrevistas semiestruturadas foram gravadas, transcritas e submetidas à análise, a qual se fundamentou na priorização das falas de modo a desvelar seus sentidos e significados mediante uma análise dialética, percebendo-as enquanto parte integrante da totalidade. Ademais, foram classificadas conforme a ordem cronológica das famílias entrevistadas (F1 até F16) com designação do parentesco em relação ao familiar adoecido.

\section{Resultados e discussão}

\section{Perfil das famílias com parente em adoecimento mental atendidas no Serviço Social da DPU/CE}

A Defensoria Pública da União constitui-se órgão permanente de atuação federal, fundamentada por determinação constitucional e pela Lei Complementar n. ${ }^{\circ}$ 80, de 12 de janeiro de 1994, e está estruturada para garantir defesa judicial e extrajudicial dos direitos individuais e coletivos, de modo integral e gratuito, aos classificados na condição de necessitados.

O Serviço Social da instituição, por sua vez, atua de modo a garantir acesso e efetivação dos direitos sociais dos usuários mediante acolhida e escuta sensível e/ ou realização de visitas domiciliares e institucionais, estudos, relatórios, perícias e laudos sociais numa perspectiva holística na qual se mesclam o particular, o 
singular e a totalidade, elementos que compõem o que Guerra (2007) chama

de instrumentalidade do Serviço Social com nuances críticas e transformadoras.

Quanto ao perfil das famílias com demanda psiquiátrica atendidas e selecionadas no período definido, 56 no total, tem-se as seguintes características consolidadas a partir do tratamento estatístico com apresentação dos percentuais mais expressivos:

a) Há um equilíbrio entre a tradicional família nuclear e as configurações mais contemporâneas, monoparental e ampliada, sendo, respectivamente, $30 \%$, 29\% e 27\% para cada. Ou seja, percebe-se, como aponta Trad (2010), que na atualidade não se fala mais em família, um tipo predominante, mas em famílias, as quais se misturam no contexto societário.

b) Quanto à composição, 32\% apresentam até três integrantes e 30\%, de cinco a oito. Logo, são famílias que apresentam um número de componentes relativamente considerável quando se percebe que geralmente a renda é obtida apenas por um dos membros, os quais, muitas vezes, sobrevivem apenas com o Benefício de Prestação Continuada (BPC) recebido pelo doente mental.

c) $38 \%$ apontam desemprego ou desocupação no ambiente familiar, $25 \%$ têm inserção formal em empregos de baixa remuneração e $21 \%$ se dedicam a atividades informais. A renda familiar segue essa lógica, qual seja, 37\% sobrevivem com um salário-mínimo, 30\% com até um salário-mínimo e meio e $14 \%$ com menos de um salário-mínimo. Assim, predominam as famílias em situação de vulnerabilidade econômica;.

d) Recorrem à DPU/CE 89\%, a fim de buscar assistência jurídica para concessão do BPC ao parente com sofrimento mental, negado no Instituto Nacional do Seguro Social (INSS). Ou seja, a judicialização dos direitos sociais é uma realidade que ratifica as agruras de um momento social que desrespeita as conquistas formais em nome da lógica capitalista (AGUINSKY; DE ALENCASTRO, 2006).

e) A grande maioria das famílias monoparentais e ampliadas são chefiadas pela figura feminina, sendo $75 \%$ na primeira e $80 \%$ na segunda. Quanto ao cuidador, em todos os tipos de famílias predomina também o gênero feminino, a saber: em 54\% é a mãe; 17\%, a irmã; e 9\%, a esposa. Figuras masculinas aparecem com percentuais ínfimos. 
f) Em relação ao parente com transtorno mental, $57 \%$ são do sexo masculino e concentram-se em faixas etárias jovens, quais sejam, $23 \%$ ficam entre 30 39 anos e $20 \%$ na faixa de 18-29 anos. Os diagnósticos que mais apareceram foram a esquizofrenia, $39 \%$, e o retardo mental, $23 \%$. A escolaridade dos parentes com transtorno mental é baixa, $42 \%$ abandonaram a escola sem completar o ensino fundamental.

\section{Dilemas e vicissitudes das famílias pesquisadas: um recorte da realidade}

O recorte da realidade para este artigo foi o cenário da desinstitucionalização psiquiátrica em Fortaleza. Sobre o modelo vigente na capital cearense, dados dos sites da Secretaria Municipal de Saúde e do Cadastro Nacional de Estabelecimentos de Saúde (CNES/2014) apontam a seguinte configuração da rede em saúde mental na atualidade: 14 CAPS, três residências terapêuticas, duas ocas comunitárias, uma cooperativa social (COOPCAPS), 11 unidades de acolhimento, 11 comunidades terapêuticas conveniadas e três hospitais psiquiátricos conveniados no Sistema Único de Saúde (Hospital de Saúde Mental de Messejana/180 leitos, rede pública; Hospital São Vicente de Paula/130 leitos e Instituição Espírita Nosso Lar/160 leitos, ambos da rede privada.

Ademais, seguindo as diretrizes do modelo, são disponibilizados leitos em hospitais gerais. Ainda segundo o CNES/2014, estão disponibilizados 17 leitos, sendo um no Hospital Infantil Albert Sabin, quatro no Hospital Universitário Walter Cantídio e 12 na Santa Casa da Misericórdia de Fortaleza. Observase, pois, que a oferta desses leitos ainda se apresenta em número reduzido se comparada à disponibilidade de leitos psiquiátricos das instituiçōes psiquiátricas.

$\mathrm{Na}$ análise das entrevistas, apresentada a seguir, foram apontados aspectos que se basearam na perspectiva das 16 famílias com parente em adoecimento mental, os quais permitiram o alcance do objetivo proposto: desvelar os dilemas e vicissitudes do segmento no contexto hodierno da desinstitucionalização psiquiátrica.

Em princípio, questionou-se sobre como as famílias lidam com o transtorno mental no cotidiano e com as divisões de responsabilidades nos grupos. Ressalvase que outros pontos foram emergindo, conforme as explanações e interesses dos entrevistados. Assim, iniciaram suas falas relatando como a doença se principiou: 
Ela era evangélica, aí arranjou um namorado que não era da Igreja, aí do meio pro fim não podia namorar, ficou com aquela culpa, depois de tudo engravidou dele. Mas ele casou com ela, mas daí ele largou ela quando as crises ficaram mais fortes, isso depois da gravidez. E ela voltou pra casa da mãe com a filha. A vida da minha mãe virou uma confusão e da família toda. Nós somos seis irmãs e um irmão, cada um mora na sua casa. Mãe morava só, continua crente da mesma igreja que minha irmã ia, e ficou com minha irmã e a neta. [...] Na primeira crise forte, minha irmã pegou a menina e se trancou dentro de casa com essa menina, aí pegou uma faca. Mulher, é uma loucura! Mãe entrou em desespero. Quando a gente chegou, já tava assim. E o SAMU não vinha. Vizinhos ajudaram. A gente amarrou os pés dela e as mãos e levou pro Hospital de Messejana. [...] Mulher, minha mãe é complicada, sabe? Ela não aceita a doença, diz que é diabo. Só quando a coisa aperta que aceita. [...] E aí agora ela engravidou de novo, e ninguém sabe quem é o pai. Não era pra pegar essa gravidez. Minha mãe não dorme mais. Está só no sofrimento. Os olhos dela são da cor de pimenta, que ela não dorme. Acho que ela tem medo dela fazer algo com ela. [...] E aí a gente ajuda, corre de um lado, corre de outro. É muito, muito pesado! (Irmã, F16).

No transcorrer das entrevistas, elementos outros emergiram: as percepções das famílias sobre a desinstitucionalização psiquiátrica, a relação delas com o poder público, materializada através dos CAPS, e outros aspectos não menos importantes.

$\mathrm{Na}$ terça a mãe dele levou ele no CAPS de manhã, mas não tinha médico lá e pediram pra ele voltar à tarde. Ela voltou e ele foi atendido às 5 horas da tarde. Deram uma injeção e eles voltaram pra casa. [...]. Ele passou a semana trancado no quarto. Quando foi no domingo, eu e meu marido, a gente tava no sítio, ligaram pra gente aflitos: 'Pelo amor de Deus, venham pra cá, C. M. tá em crise, ele tem que ser medicado, porque do jeito que ele tá aí pode surtar e fazer alguma coisa com alguém ou com ele mesmo'. [...] Chegando lá, a gente levou pro CAPS, mas tava fechado. [...] Levamos pro Hospital de Messejana e deram uma injeção. Voltou pra casa de novo. Na segunda, minha sogra levou ele pro CAPS, e outra injeção foi dada e disseram que ele podia voltar pra casa. Chegou lá, ele emburacou no quarto e só foi sair de noite. [...] Era 10 horas da noite. Tava na casa meu sogro, minha sogra, meu cunhado e cunhada. Segundo minha sogra fala, ele chegou na sala já gritando e ordenando que a luz da sala se apagasse - ele tava falando com a lâmpada. Ele dizia que era Deus e que a luz tinha que obedecer. E como não obedeceu, começou a gritar mais alto. Meu sogro foi pedir pra ele não falar alto porque incomodava os vizinhos. Primeiro ele deu um murro no pai, um senhor de 71 anos, que caiu no chão desacordado. Os outros entraram em desespero, procuravam a chave da casa. Nesse instante, ele correu na cozinha, pegou uma faca de serrinha. Primeiro ele atingiu o meu cunhado, o caçula, com vários golpes. E aí minha cunhada bateu nele com uma cadeira. Ele deu um murro nela. Aí minha sogra tentou agarrar ele pelas costas, ele empurrou ela com força que ela bateu a cabeça na parede. Minha cunhada correu e se escondeu pro quarto dela pedindo socorro. E aí ele foi na direção do pai e esfaqueou até ele morrer. O cunhado, o que se feriu, conseguiu pular a janela e pediu ajuda. Nisso, lá fora, a rua já tava cheia de gente, o povo gritando, ligando pro SAMU, pra polícia, 
tudo que você possa imaginar, entendeu? Foi quando conseguiram arrombar a porta e um vizinho atingiu ele com um negócio pesado, que não sei o nome, aí a polícia chegou. Foi uma tragédia, mulher! [...] Depois de um ano, no Instituto Psiquiátrico Governador Stênio Gomes, ele voltou para casa. Lá ninguém fala do que aconteceu, mas a atenção é total nele. A gente vive de olho, entende? No CAPS, ele é atendido sempre que vai, porque dizem que ele é especial. E aí disseram que o diagnóstico dele agora é esquizofrenia com bipolaridade. Por que mudaram só depois de acontecer o que aconteceu? (Cunhada, F9).

Além dessas turbulências emocionais e dos acontecimentos traumáticos que redundaram em mudanças na dinâmica familiar, um aspecto recorrente em particular chamou a atenção: a cooperação e o apoio entre seus integrantes. Isso constituiu uma marca presente na fala dos entrevistados de todos os tipos familiares.

Foi o irmão que abandonou o emprego e ficou à mercê da irmã e dos sobrinhos esquizofrênicos: "Eu tive que deixar o emprego e ficar como motorista de minha irmã. [...] Lá em casa a gente evita discutir perto deles" (Tio, F1). Filhos, tios, cunhada e outros parentes, com ou sem consanguinidade, mas ligados por laços afetivos - muitos que já têm suas próprias formaçōes familiares - deliberadamente se oferecem para prestar auxílio diante do sofrimento dos grupos.

Tais acontecimentos corroboram as considerações de Sarti (2011), ao explanar que uma das características preponderantes das famílias mais vulneráveis consiste na sua configuração em rede ("famílias enredadas"), ou, segundo Osterne (2001), no fato de que o grupo familiar assume-se como unidade de referência, ou seja, lugar de pertencimento, espaço onde é possível experimentar sensação de segurança afetiva, emocional ou mesmo material.

Contudo, o aumento da procura pelos laços de solidariedade na rede familiar também pode estar relacionado à desresponsabilização do poder público no atendimento dos serviços sociais destinados a essas famílias, uma vez que "a ausência de proteção pública reforça o laço de dependência entre as pessoas" (OSTERNE, 2001, p. 25). Seguem depoimentos que apontam pra essa questão e permitem outras análises:

Meu filho é atendido no CAPS lá perto da Barão de Studart, esqueci o nome da rua, mas é lá. Atendido para pegar a receita. Sabe de quanto em quanto tempo? Seis meses. De seis em seis meses. É incrível, se falar isso, dá até vergonha. Aí o médico diz assim: 'Olha, você veio em fevereiro, agora venha só em agosto'. É desse jeito. Demora seis meses. Daí, não tem jeito, a gente tem que se virar, porque ele tem crise e precisa ser atendido. $\mathrm{O}$ jeito foi correr atrás do benefício dele, que, graças a Deus, conseguiu pela DPU, pra gente ir atrás também do psiquiatra particular, porque se esperar só de lá ele fica terrível. Eu acho um absurdo, mas o que a gente pode fazer? Ele toma Losapina, 
único remédio que tá controlando mais as crises, mas é difícil a gente conseguir, e aí tem que comprar, custa $\mathrm{R} \$ 300,00$. [...] Teve uma vez que ele ficou muito mal, uma crise braba, pegou faca e tudo, aí eu e a mulher, a gente decidiu que não tinha jeito, tinha que internar. Aí a gente foi no Hospital de Messejana e não achou vaga. E lá diziam pra gente: 'Olha, se você quer internar, vai ter que fazer como aquelas pessoas'. Tinha um bocado no chão, tudo dormindo no chão do Hospital. Então eu falei: 'Meu Deus do céu, é muita humilhação'. E outro dizia: 'Você tem que ficar deitado aí até surgir uma vaga, que ninguém sabe se é um dia, dois, três'. E outra, quando eu olhava lá dentro, eu via só o inferno, porque os doentes amarrados, gritando. Aí ela, minha esposa: 'Meu Deus, eu prefiro amarrar ele lá em casa do que amarrar aqui. E assim a gente fez, amarrou ele lá em casa até ele se acalmar. (Pai, F15).

A primeira internação dele foi quando tava com 22 anos, em 2007, no Hospital Nosso Lar, e ficou seis meses. Daí o médico encaminhou pro Hospital de Messejana, mas de lá disseram que ele tinha que ir para o CAPS. Levei, mas, quando chegou lá, não quis ficar. Quando tinha que ir, ele fugia. Dizia que tinha estudo - ele é formado em técnico de enfermagem e fazia engenharia mecânica, mas abandonou por causa da doença - e no CAPS o povo não sabia de nada. Aí fiquei só recebendo a receita. E aí minha irmã um dia foi comigo e disse que também não tinha gostado, que lá o povo não orientava direito, que o serviço era lotado, faltava psiquiatra e que era por isso que o sobrinho não queria ir. Aí a família se juntou e fez o plano de saúde dele. Hoje ele tá internado pelo plano de saúde na Clínica Despertar faz três meses, mas a gente teve que entrar com uma liminar porque a UNIMED não queria pagar a internação. Doutora, eu não queria, não queria meu filho doente, não, nem internado, mas ele surta muito e tem a droga também. Já me bateu. Só Deus na minha vida, por isso tô na Igreja Mundial. Acho que tem coisa do espírito também. [...] Vou uma vez no mês lá na clínica pra visitar ele, toda a família com os doentes juntos. [...] Eu tenho que dar R \$ 300,00 na mercearia da clínica para merenda extra. Lá dão cinco refeiçôes. Ainda bem que ele ganhou pela DPU o benefício. [...] Lá ele tem as medicações, mas, quando voltar para casa - vai ficar mais três meses lá -, vai precisar dos remédios. Quando ele está comigo, preciso ir até o CAPS para pegar a receita e os remédios. Se eu falar que ele tem plano de saúde, eles não me dão. Mas as consultas ele só vai no médico dele, do plano de saúde. [...] Quando falta remédio no CAPS, que costuma faltar, minha irmã ou sobrinhas compram pra mim (Mãe, F5).

Como se observa, além da rede de apoio familiar, as falas demonstram que a política de saúde mental convive com dois modelos díspares: a desinstitucionalização psiquiátrica, que pelos relatos indica o não atendimento a contento, e os resquícios do modelo hospitalocêntrico assumidos principalmente por setores privados com interesses mercadológicos.

Vasconcelos (2010) assevera que o momento é desafiador em face da expansão de um longo histórico de políticas neoliberais que induzem à precarização das políticas públicas e, por conseguinte, causam prejuízos à universalização e à efetivação da desinstitucionalização e direitos sociais de responsabilidade do Estado. 
No caso das famílias que dependem única e exclusivamente do serviço público, devido às carências e à realidade econômica adversa, seus entes adoentados ficam reféns de ações repletas de lacunas e deficiências, como é possível perceber nos relatos:

Foi o posto de saúde que encaminhou minha irmã para o CAPS do Bom Jardim. Quando eu fui lá, isso há dois anos, sempre tá faltando médico. Só que agora o caso lá está mais sério. Não tem médico! É tanto que você chega lá, num instante fazem a ficha e só. E aí a gente espera a receita que a enfermeira dá. Se tiver medicação, eu recebo, se não tiver, eu vou comprar. [...] Uma vez eu falei desesperada que a medicação não tava mais servindo, que minha irmã tava muito mal. Tive que brigar, gritar para ver um médico. Aí eles disseram que $i a$ tentar um médico de plantão. Só depois de criar confusão, apareceu um, mas nem é de lá, disseram que arrumaram de não sei onde. Não tem médico (Irmã, F14).

Meu irmão tem doze anos de CAPS, nunca faltou uma vez, ele vai todo dia. De manhã se arruma e segue pro CAPS do Rodolfo Teófilo. Ele se sente bem lá. Ele coloca pra gente que antes era melhor, que tinha sete psiquiatras e agora só tem um e que ele não dá conta do povo pra atender. Eu bem acho que ele não saiu porque é concursado. Meu irmão diz assim: 'Tá acabando os médicos lá. Na época de Luizianne [ex-prefeita de Fortaleza], não era assim. Nem lanche a gente tem também todo dia'. Ele é sabido, percebe as coisas. [...] Ele fica triste com isso, porque disse que gosta muito do pessoal de lá (Irmãos, F6).

Todos os entrevistados expressaram desilusão com os CAPS, a qual se materializa na falta de médicos, consultas prolongadas - isso quando eles conseguem ver o profissional psiquiátrico, uma vez que saem de lá apenas com as receitas entregues pelos enfermeiros -, indisponibilidade das medicações nos setores de entrega, estrutura física improvisada e inadequada dos CAPS, rotatividade dos profissionais, falta de ambulância psiquiátrica para condução de pacientes em crise, Serviço de Atendimento Móvel de Urgência (SAMU) com atraso e equipe sem preparo para atender casos específicos de saúde mental, dentre outras queixas.

As críticas em torno da situação foram lançadas nos respectivos centros de atenção também por eles serem a porta de entrada do modelo e constituírem espaços nos quais os problemas estão expostos e mais próximos dos usuários e familiares. Poucos fazem uma leitura mais ampliada no sentido de ver a situação como uma questão política e de cunho mais amplo.

$\mathrm{Eu}$ acho que esse modelo CAPS foi positivo. O interessante é que eles realmente abraçam a causa, porque nos hospitais é muita gente e não tem como acompanhar. $\mathrm{E}$ as pessoas mentais não são apenas doentes, não precisam somente tomar medicação, 
precisam de certo cuidado. Num hospital psiquiátrico, eu já acompanhei, eles tratam

todos que nem bicho. Dão a medicação e jogam lá. No CAPS 24 horas, não. Meu irmão já teve lá. Ali a família fica interagindo, já vai lá todo dia, porque eles já têm essa norma de ligar e tudo. O problema é que a demanda é grande e não dá conta. Tem quer ter mais CAPS, mais condições. Desse jeito que tá é ruim. Improvisar um CAPS numa casa, sem médico, sem remédio, sem profissionais, como vai funcionar bem? (Irmã, F13).

A grande maioria, entretanto, enfatiza veementemente sua desilusão com o CAPS e a descrença em sua funcionalidade, em face das experiências negativas pelas quais passou:

CAPS também não adianta. A gente vai lá e não tem médico, não tem medicação, não tem gente preparada - disseram que o problema dele era birra, e ele é esquizofrênico. Eu tive que ler e pesquisar pra saber o que era isso. Prefiro que ele seja atendido no NAIA $^{1}[\ldots]$. Eu digo pra senhora, não funciona, e é por experiência própria e pelo que vejo quando levo meu filho nas consultas no NAIA, lá no Hospital de Messejana. Ali, na porta de entrada do Hospital, a maioria das mães são do interior, porque lá os CAPS não funcionam. Aí elas se humilham nas Prefeituras pra conseguir transporte. Sair de casa duas horas da madrugada pra eles deixarem elas lá cinco horas da manhã e ficarem esperando até cinco horas da tarde.Quando o psiquiatra disse que ia me encaminhar de novo pro CAPS, eu disse: 'Não, por favor, eu não quero voltar para lá. Diga, doutora, o que eu vou fazer num lugar desse?' [...] É que no CAPS, em si, numa palavra bem dura mesmo: o CAPS é uma farmácia que não funciona. Se fosse para pensar numa coisa que funcionasse, porque dinheiro tem, que construísse um CAPS em cada bairro, perto da casa da gente [...] com leitos separados por doença mental, esquizofrenia, retardo mental, gente doente por causa de droga; não misturar tudo quanto. Se tem isso, não vi ainda funcionar (Mãe, F1).

Seja na expressão mais negativa, seja na fala que vislumbra alguns pontos positivos, atentar para as vozes dos familiares, suas lamentações e desilusões, subsidia no desvelamento de seus dilemas e vicissitudes. Ademais, Vasconcelos (2010) alerta para o perigo de desprezar as demandas e necessidades familiares, visto que isso cria aberturas arriscadas para possíveis cooptaçóes dos segmentos por setores ligados a interesses e posturas conservadores.

Pelas demandas expostas nos depoimentos, há de se reconhecer que as famílias estão quase na unilateralidade. Não totalmente, uma vez que os grupos recebem atendimentos nos espaços de implementação da proposta e, portanto, há uma coparticipação entre famílias e instituiçōes de saúde mental. Entretanto, é uma coparticipação fragilizada, visto que tais serviços prestados, de responsabilidade do poder público, não seguem as diretrizes em sua integralidade, especialmente na atenção e cuidados destinados aos parentes adoecidos. 
Em relação à acolhida, ao engajamento e à participação nos processos decisórios dos familiares na realidade dos CAPS, os depoimentos apontaram que a inserção primeira decorre da crise psicótica após um período de internação no Hospital de Saúde Mental. A acolhida foi postulada como satisfatória, tanto pela equipe de apoio quanto pelos profissionais de base, não obstante as reclamações pelas péssimas condições de atendimentos e ausência constante dos médicos psiquiatras. E, por fim, não houve qualquer sinalização que apontasse participação dos familiares em decisões institucionais.

Eu fui bem acolhida com meu marido pela equipe toda. O pessoal foi gentil. Nossa! A assistente social de lá [...] maravilhosa. Teve uma que saiu de lá, a primeira psiquiatra. Ah! Outra coisa, não sei os outros CAPS, mas ali já tivemos duas mudanças. Era uma, depois já passou pra outro. E parece que esse já vai sair. Disseram que ele vai sair. Eu estou gostando desse, embora ele fale pouco e a consulta seja de três em três meses [...] Aí eu já estou com esse e tá certinho, está tudo bonitinho, e de repente vem outra. Não sei, acho que não é legal. [...] Como eu disse pra senhora, acaba que a gente fica mais em casa mesmo e tem nossa neta que minha filha deixa aqui quando vai trabalhar. E, assim, o que tem lá não é melhor do que o que ela tá fazendo com a gente, desculpa, mas não é (risos) (Esposa, F 10).

O suporte socioterapêutico do CAPS direcionado às famílias foi um aspecto bastante trabalhado. Houve quem apontasse que a prática de grupos com família era mais comum em períodos anteriores: “Tinha reunião de orientação, umas palestras. Mas, como é longe, acabava que não dava pra ir. Hoje nunca mais ouvi falar. A gente chega lá e só é mais é confusão, falta de médico” (Mãe, F3).

Em relação às visitas domiciliares da equipe, todas as famílias foram enfáticas no sentido de realçar que nunca receberam acompanhamento na residência, nem mesmo uma visita rotineira: "Nunca falaram dessa proposta de visita, não. Nunca foram. Rapaz, seria uma beleza! Eu ia aceitar de coração, porque ele tem esse negócio de ficar isolado. Até nas consultas é difícil tirar ele de casa” (Pai, F15).

$\mathrm{O}$ atendimento psicológico, visto que as famílias apontaram adoecimento em razão da sobrecarga emocional, foi também colocado com frequência. Das dezesseis famílias, apenas três foram vistas pelo profissional de psicologia. As demais, ao contrário, apontaram que até para o parente com sofrimento mental as consultas psicológicas são demoradas em razão também da demanda excessiva.

Antigamente nossa mãe, ela fazia comida, ela fazia as tarefas de casa. Hoje em dia, ela não sai do portão de casa. Ela arriou depois da doença do meu segundo sobrinho, vive no fundo de uma rede. Precisa de psicólogo, ela tá com depressão. Eu também 
tive um problema aí e também tô precisando. Isso tudo mexe com os nervos da gente.

Para eu ir pro CAPS receber uma vaga, só são três vagas por dia, tem que ir de manhã, tem que ir de madrugada, três de manhã e três de tarde. Está com mais de um mês que estou atrás de vaga, até então não consegui. O CAPS resolve o quê? E outra coisa, eles alugam uma casa. É uma casa! (Tio, F1).

Como pergunta final, solicitou-se que cada representante familiar elencasse as principais dificuldades referentes tanto ao seu parente com sofrimento psíquico quanto à condição da família. Seguem as mais preponderantes, as quais foram divididas nas duas categorias específicas.

Em relação ao parente, destacam-se: o sofrimento acarretado pelo transtorno mental, que não tem cura; o medo pelo futuro deles, especialmente os que ainda não dispõem do $\mathrm{BPC}$; as crises recorrentes pela falta de atendimento médico e medicamentoso; e o preconceito social.

Em relação à condição familiar, predominam: os problemas financeiros e as carências para suprir as necessidades do parente com transtorno mental; a sobrecarga em razão da falta de assistência psiquiátrica na rede de saúde mental; e o adoecimento familiar.

\section{Considerações finais}

Como pistas reflexivas deste trabalho, ficou a certeza de que as famílias socialmente vulneráveis com parente em situação de transtorno mental, mais do que nunca, precisam ser vistas. E razões para isso não faltam. $\mathrm{O}$ contexto familiar de adoecimento mental já traz em si inúmeras tensões e conflitos, e quando essa realidade se mescla a uma conjuntura marcada por adversidades, conforme desvelado, os dilemas e vicissitudes se agudizam e tomam dimensões extremamente complexas.

É preciso ouvir seus gritos. É preciso atentar para suas demandas. Percebeuse, nos depoimentos dos representantes familiares, uma espécie de clamor por atenção no intento de melhorar a política de saúde mental. "Espero que a gente tenha voz e, quem sabe futuramente, uma oportunidade de tentar mudar o que está faltando na nossa saúde mental", disse uma mãe cansada e sufocada pelas lutas diárias.

Como numa canção de Don Mclean, escrita em tributo a Van Gogh ${ }^{2}$ no ano de 1971, cujo refrão diz: "Agora eu entendo o que você tentou me dizer. E o 
quanto sofreu pela sua lucidez. E como você tentou libertá-los. Eles não ouviram. Não sabiam como. Talvez agora ouçam”. Espera-se, tal qual no sentido da letra, que as vozes das famílias aqui expressas possam ecoar e chegar aos profissionais de saúde mental, às lideranças e às associaçôes reformistas que seguem na luta em defesa da desinstitucionalização psiquiátrica, aos gestores de saúde mental e a todos que acreditam no modelo como ganho e conquista de liberdade.

Se algumas famílias apontam na direção da desesperança, do descrédito e culpabilizam os CAPS e a proposta da desinstitucionalização, não o fazem sem razão. Efetivamente, a situação é difícil para esses grupos. Eles sentem e vivenciam os problemas de perto. E o "inimigo" visível aos olhos deles é quem está passível de ser visto, ou seja, as instituições que prestam serviço em saúde mental.

Em suma, se a desinstitucionalização, por um lado, possibilita o tratamento de seus familiares com foco humanizado, por outro, é razão de grandes frustrações em virtude de a oferta ser incompleta, pelas condiçôes objetivas do atendimento: restrição no número de atendimentos; falta de médicos e medicamentos; infraestrutura inadequada; exclusão da opinião dos familiares nas mudanças gerenciais; falta de apoio psicológico aos familiares, entre outras carências. Diante disso, as famílias acabam recorrendo ao modelo convencional que os explora financeiramente, além de oferecer tratamento retrógrado, desumano e, muitas vezes, ineficaz.

Cabe aos defensores do modelo em curso persistirem na semeadura no sentido de mudar essas percepções, mas com ações reais na direção desses clamores, usando de paciência nas dificuldades, sensatez nas escolhas, delicadeza nas palavras, coragem nas provas e pinceladas de muito amor. Amor expressa cuidado. E cuidado é a palavra-chave da desinstitucionalização. A luta é árdua, os desafios são imensos - não é fácil lidar com questões estruturais -, mas a história prova que não é impossível superar os entraves postos. Afinal, é na realidade que se encontram as possibilidades. ${ }^{3}$

\section{Referências}

AGUINSKY, B. G.; DE ALENCASTRO, E. H. Judicialização da questão social: rebatimentos nos processos de trabalho dos assistentes sociais no Poder Judiciário. Revista Katálysis, v. 9, n. 1, p. 19-26, 2006. 
BRASIL. Ministério da Saúde. Secretaria de Atenção à Saúde - CNESNet/DATASUS.

2014. Disponível em: <http://cnes.datasus.gov.br/Mod_DownLoad_Documentacao. asp>. Acesso em: 06 jan. 2015.

. Ministério da Saúde. Secretaria de Atenção à Saúde. DAPES. Coordenação Geral de Saúde Mental, Álcool e Outras Drogas. Saúde Mental no SUS: as novas fronteiras da Reforma Psiquiátrica. Relatório de Gestão 2007-2010. Brasília: Ministério da Saúde 2011, 106 p. Disponível em: <http://bvsms.saude.gov.br/bvs/publicacoes/ saude_mental_ fronteiras_reforma_psiquiatrica.pdf $>$ Acesso em: 21 mar. 2015.

CARVAlHO, M. C. B. de. A família contemporânea em debate. São Paulo: Cortez, 2001.

CASTEL, R. A dinâmica dos processos de marginalização: da vulnerabilidade à "desfiliação". Cadernos CRH, n. 26 e 27, p. 19-40, 1997.

. A ordem psiquiátrica: a idade de ouro do alienismo. Tradução de Maria Thereza da Costa Albuquerque. Rio de Janeiro: Graal, 1978.

DELGADO, P. G. Sobrecarga do cuidado, solidariedade e estratégia de lida na experiência de familiares de Centros de Atenção Psicossocial. Physis: revista de saúde coletiva, Rio de Janeiro, v. 24, n. 4, dez. 2014. Disponível em: <http://www.scielo. br/scielo.php?script=sci_ arttext\&pid=S0103-73312014000401103\&lng=pt\&nrm=iso >. Acesso em: 30 mar.2015.

DIMENSTEIN, M. et al. Estratégia da Atenção Psicossocial e participação da família no cuidado em saúde mental. Physis: Revista de Saúde Coletiva. Rio de Janeiro, v. 20, n. 4, p. 1209-1226, dez 2010. Disponível em: <http://www.scielo.br/pdf/physis/v20n4/ a08v20n4. pdf>. Acesso em: 10 mar. 2015.

FOUCAULT, M. A história da loucura na idade clássica. Tradução de José Teixeira Coelho. São Paulo: Perspectiva, 2012.

GOFFMAN, E. Manicômios, prisões e conventos. Tradução de Dante Moreira Leite. São Paulo: Perspectiva, 2013.

GUERRA, Y. A instrumentalidade do Serviço Social. 5 ed. São Paulo: Cortez, 2007.

MCLEAN, D. V. Intérprete: MCLEAN, D. In: . American Pie. Record Plant Studios, New York City, p1971. 1 CD, faixa 3.

MIOTO, R. C. T. Novas propostas e velhos princípios: a assistência às famílias no contexto de orientação e apoio sociofamiliar. In: SALES, M. A.; MATOS, M. C. de; LEAL, M. C. (Org.). Política social, familia e juventude: uma questão de direitos. 5 ed. São Paulo: Cortez, 2009.

OSTERNE, M. do S. F. Família, pobreza e gênero: o lugar da dominação masculina. Fortaleza: EDUECE, 2001.

PEREIRA, P. A. P. Mudanças estruturais, política social e papel da família: crítica ao pluralismo de bem-estar. In: SALES, M. A.; MATOS, M. C. de; LEAL, M. C. (Org.). Política social, família e juventude: uma questão de direitos. 5 ed. São Paulo: Cortez, 2009. 
PIZARRO, R. La vulnerabilidad social y sus desafios: una mirada desde América Latina. Santiago de Chile: Publicación de las Naciones Unidas/CEPAL/ECLAC, 2001.

SARTI, C. A. A família como espelho: um estudo sobre a moral dos pobres. 7 ed. São Paulo: Cortez, 2011.

TEIXEIRA, S. M. A família na política de assistência social: concepçôes e as tendências do trabalho social com famílias nos CRAS de Teresina. Teresina: EDUFPI, 2013.

TRAD, L. A. B. Família contemporânea e saúde: significados, práticas e políticas públicas. Rio de Janeiro: Fiocruz, 2010.

VASCONCELOS, E. M. Desafios politicos da Reforma Psiquiátrica brasileira. São Paulo: Hucitec, 2010.

\section{Notas}

${ }^{1}$ Núcleo de Atenção Integral à Infância e Adolescência do Hospital de Saúde Mental de Messejana. Presta atendimento multidisciplinar a crianças e adolescentes com transtornos mentais.

${ }^{2}$ Pintor holandês do século XIX acometido por transtorno mental e com histórico de internação em instituições psiquiátricas da época. Suicidou-se em 1890. Sua obra e genialidade só foram reconhecidas após sua morte.

${ }^{3}$ T. B. Gomes realizou a análise e a redação do artigo. J.B.F. dos Santos realizou a discussão e a revisão analítica do artigo. 


\section{Dilemmas and setbacks of families in social vulnerability in the context of psychiatric deinstitutionalization}

This article aimed to unveil the dilemmas and setbacks in the lives of families in situations of social vulnerability within today's context of psychiatric deinstitutionalization. The quanti-qualitative research was based on specialized bibliography, documents, semi-structured interviews and floating observation, was carried out at the Public Defender's Office whose subjects are families with psychiatric demands assisted by the institution's Social Service and seek for legal assistance to guarantee mentally impaired people the social rights that had been denied to them at the administrative scope. The study found that the members of these families face dilemmas and setbacks both on the micro-familiar level, through conflicts involving financial, physical and emotional matters marked by the pressure and the overload of the situation as a whole; as well as on the macro-social level, due to the growing process of family centralization before the lack of State protection and the structural illnesses of a policy based on global and economic interests that echoes into the promotion of social protection policies. Therefore, one concludes that such issues need to be widely discussed in order to closely observe these families' demands, since not meeting their needs may incur risks to the advances of psychiatric deinstitutionalization.

Key words: family; social vulnerability; psychiatric deinstitutionalization. 